\title{
Vibratory territorial signals in caterpillars of the poplar lutestring, Tethea or (Lepidoptera: Drepanidae)
}

\author{
JACLYN L. SCOTT and JAYNE E. YACK \\ Department of Biology, Carleton University, 1125 Colonel By Dr., Ottawa, ON, K1S 5B6 Canada; \\ e-mail: jyack@connect.carleton.ca
}

Key words. Drepanidae, Thyatirinae, Tethea or, larva, defense, vibration, communication, mandible scraping, territory, leaf shelter

\begin{abstract}
Caterpillars of the poplar lutestring moth, Tethea or, construct leaf shelters that they defend against intruding conspecifics using a combination of vibratory signals and physical aggression. Staged interactions between a resident caterpillar and introduced conspecific were recorded with a video camera and laser vibrometer. Residents crawl towards the intruder and perform three behaviours: lateral hitting, pushing, and mandible scraping. Vibrations caused by mandible scraping result from the caterpillar repeatedly scraping opened mandibles laterally against the leaf surface in bouts lasting $1.16 \pm 0.39 \mathrm{~s}$, with an average of $4 \pm 1$ scrapes per bout. We propose that these scrapes function in leaf shelter defense against conspecifics for the following reasons: Mandible scrapes are produced only by residents; they are generated when a resident is approached by an intruder; the rate of scraping increases as the intruder approaches the shelter; and residents in all trials retain their shelters, with the intruder leaving the leaf within 127.9 $\pm 104.3 \mathrm{~s}$ from the beginning of the trial. The function and evolutionary origins of vibration-mediated territoriality in caterpillars are discussed.
\end{abstract}

\section{INTRODUCTION}

The construction of leaf shelters by caterpillars is widespread among at least 18 families of Lepidoptera (Scoble, 1992) and can play an important role in an individual's survival. Leaf shelters are constructed by rolling, folding or tying leaves together with silk, or building webs or tents (Cappuccino, 1993; Lill et al., 2007) and are believed to provide many benefits, including a favorable microclimate, protection from natural enemies and dislodgement, and improved food quality (Fukui, 2001). As such, caterpillars that expend time, energy and material (silk) constructing their own shelters may be expected to defend these valuable commodities from intruding conand heterospecifics. Caterpillars have been reported to defend resources using physical aggression, including striking with the head (e.g., Oecophoridae, Depressaria pastinacella Duponchel: Berenbaum et al., 1993), biting (e.g., Noctuidae, Busseola fusca Fuller: Okuda, 1989) and even killing their opponents (e.g., Pieridae, Anthocharis cardamines L.: Baker, 1983). In addition to using physical combat, there is evidence that some species use vibratory warning signals in the context of territory defense (see references below).

Vibratory communication through plants is widespread among insects (Cocroft, 2001; Virant-Doberlet \& Cokl, 2004; Cocroft \& Rodriguez, 2005; Hill, 2009), and whilst most research to date has focused on adults, there is increasing evidence that larvae of holometabolous insects also communicate using vibrations. In larval Lepidoptera for example, there is evidence that vibratory signals facilitate mutualistic relationships with ants (Lycaenidae and Riodinidae butterfly larvae: DeVries, 1990, 1991; Pierce et al., 2002) and play a role in resource defense
(Tortricidae, Sparganothis pilleriana Denis \& Schiffermüller: Russ, 1969; Drepanidae, Drepana arcuata Walker: Yack et al., 2001, Falcaria bilineata Packard: Bowen et al., 2008, Oreta rosea Walker: Scott et al., 2010a; and Gracillariidae, Caloptilia serotinella Ely: Fletcher et al., 2006). At present, it is unknown how widespread vibratory-mediated territorial defense is in caterpillars. Considering the widespread occurrence and benefits of building leaf shelters in caterpillars, vibrationmediated territoriality may be more common than previously supposed. These vibrations are mostly inaccessible to humans without specialized recording equipment, and therefore many vibratory signals may have been overlooked in the past. Further research is needed to characterize these types of signals and to test their function in the context of shelter defense in different taxa.

This study focuses on vibrational communication in the poplar lutestring caterpillar, Tethea or Denis \& Schiffermüller, which is distributed throughout Europe, Asia Minor and the Caucasus, across Russia, Siberia and Eastern Asia to Japan (Riegler, 1999). Previous reports on this species have shown that eggs are laid singly or in small groups on the underside of leaves on poplar (Populus spp.), and that caterpillars build a shelter by tying two leaves together with silk, remaining concealed within the shelter during the day and feeding at the edge of the shelter at night (Theakston, 1866; Newman 1884; Stokoe et al., 1948; Riegler, 1999). Riegler (1999) noted that when disturbed, caterpillars shake within their shelters, making a "sifflement" (whistling) or "raclement" (scraping) noise. In a recent comparative study that focused on the evolutionary origins of vibratory signals in the Drepanoidea (Scott et al., 2010b), it was reported that $T$. or residents produce vibrations by scraping their man- 

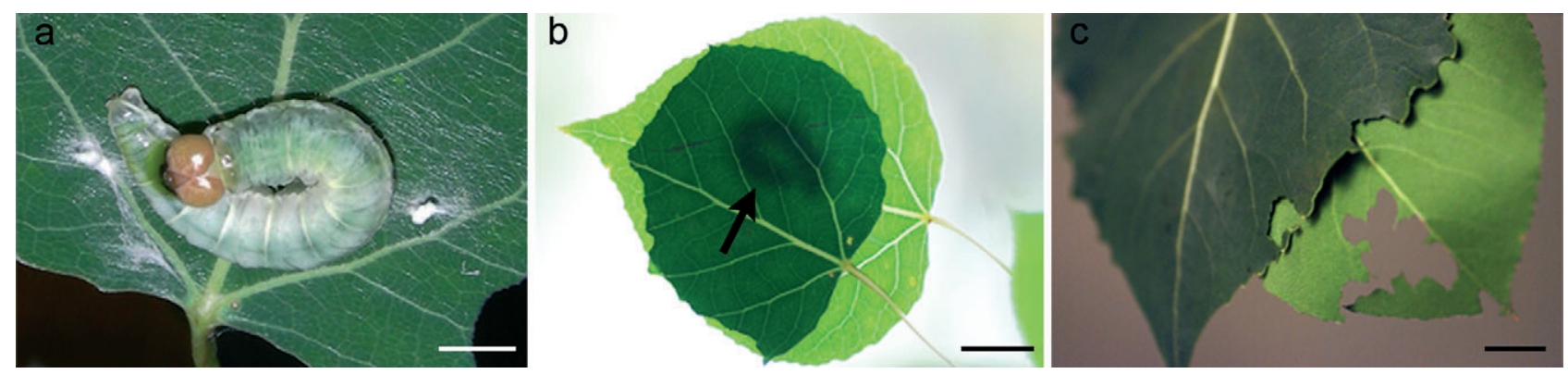

Fig. 1. Photographs of a Tethea or late-instar larva. (a) - larva in a typical U-shaped resting position (scale bar $=3 \mathrm{~mm}$ ); (b) larva (arrow) in a leaf shelter constructed between two leaves of Populus tremuloides (scale bar $=1 \mathrm{~cm})$; $(\mathrm{c})$ - evidence of feeding on the edge of the leaf shelter (scale bar $=1 \mathrm{~cm})$.

dibles on the leaf surface when approached by a conspecific. The characteristics of the vibrations and tests of their function however, were not directly studied. Our study has two specific goals: the first is to document and characterize behaviours and associated vibrations that occur during encounters between shelter residents and conspecifics. Since any behaviour may produce passive vibrations (cues), all vibrations produced during encounters were studied and assessed as signals or cues based on their characteristics (e.g., redundancy, conspicuousness) (see Discussion, and Bradbury \& Vehrencamp, 1998; Maynard Smith \& Harper, 2003). The second goal was to test the hypothesis that vibrations function in territorial behaviour. If vibrations function in territory defense, they should: (i) be produced primarily by the resident within the leaf shelter; (ii) be elicited by the approach of an intruder; (iii) escalate as the intruder approaches; and (iv) be followed by one contestant leaving the shelter, typically the intruder.

\section{MATERIAL AND METHODS}

\section{Animals}

Gravid female Tethea or Denis \& Schiffermüller, 1775 (Lepidoptera: Drepanidae: Thyatirinae) moths were collected from the wild at ultraviolet lights from June to August in 2007 and 2009 in Espoo, Finland. Females oviposited on cuttings of European aspen (Populus tremula). Early instars were fed P. tremula in Finland, and then shipped to Ottawa, Canada (Permit \# P-2007-02390), where late instars were reared on trembling aspen $(P$. tremuloides) under a $18 \mathrm{~L}: 6 \mathrm{D}$ photoperiod at $21-26^{\circ} \mathrm{C}$ in an insect rearing facility. Studies were conducted on late-instar larvae only.

\section{General observations on shelter building and occupation}

Behaviours associated with shelter building, mode of feeding, and shelter occupation, were documented using videography and photographs. Caterpillars were placed on a sprig of hostplant with multiple leaves in large glass jars $(26 \mathrm{~cm}$ tall, diameter of $15 \mathrm{~cm}$ ), and behaviours were monitored for $8 \mathrm{~h}$ using a CCD camera and time lapse video recorder, and a Nikon Digital SLR camera (D80; Tokyo, Japan).

\section{Scanning Electron Microscopy}

Mandibles were dissected from alcohol-preserved specimens, air dried, and mounted on aluminum stubs. Specimens were sputter-coated with gold-palladium and examined using a Tescan Vega-II scanning electron micrograph (XMU VPSEM; Brno, Czech Republic).

\section{Vibration recordings}

Behaviours associated with conspecific interactions were monitored simultaneously with a Sony High Definition Handicam (HDR-HC7; Tokyo, Japan) and remote Sony audio microphone (ECM-MS907), and a laser-doppler vibrometer (LDV; Polytec PDV 100; Walbronn, Germany). Vibrations were measured with the LDV by reflecting the laser beam from a circular disc of reflective tape $(2.0 \mathrm{~mm}$ in diameter) positioned on the leaf within $1 \mathrm{~cm}$ of the resident's leaf shelter. Laser signals were digitized and recorded onto a Marantz Professional portable solid-state recorder (PMD 671; Kanagawa, Japan; $44.1 \mathrm{kHz}$ sampling rate). LDV and microphone recordings in conjunction with videotapes were analyzed to determine which vibrations were associated with different behaviours, and to measure temporal characteristics (durations of signals and signaling bouts, inter-bout intervals, and number of signals per bout). A bout was defined as any combination of signals that was preceded or followed by feeding, walking or at least $1 \mathrm{~s}$ of inactivity. Spectral characteristics were measured using LDV recordings only. Power spectra were generated (15892-point Fourier transform; Hann window), and dominant frequencies and bandwidths around the dominant peak (at $-3 \mathrm{~dB}$ SPL and $-10 \mathrm{~dB}$ SPL) were calculated. Amplitudes of vibrations associated with different behaviours were measured relative to background levels, and compared between behaviours within recordings using a paired $t$-test to help assess whether vibrations were cues or signals. All signals were analyzed using Raven Bioacoustics Research Program (Cornell Laboratory of Ornithology; New York, U.S.A.) and recordings were conducted in an acoustic chamber (Eckel Industries, Massachusetts, U.S.A.).

\section{Conspecific encounters}

To study how vibrations are associated with conspecific interactions, and to test the hypothesis that signals function in territorial defense, 11 encounters were staged between a resident and an introduced conspecific. A late-instar larva was selected at random from 2 broods of wild-caught females and matched with another larva of approximately the same size. Residents were allowed to construct a shelter overnight on leaves on P. tremuloides and intruders were isolated in a container with bare twigs for at least $30 \mathrm{~min}$ prior to the trial. Trials were videotaped from $1 \mathrm{~min}$ before the intruder was introduced to the leaf twig until 1 min after one contestant left the leaf (i.e., when one contestant "won" the encounter). All trials were recorded using a Sony High Definition Handicam (HDR-HC7) and a remote Sony audio microphone (ECM-MS907) placed 1-2 cm behind the leaf. A subset of trials was also recorded with the LDV as described above.

Videotapes were analyzed to measure the durations and outcomes of contests, and to monitor changes in behaviour rates in 
a

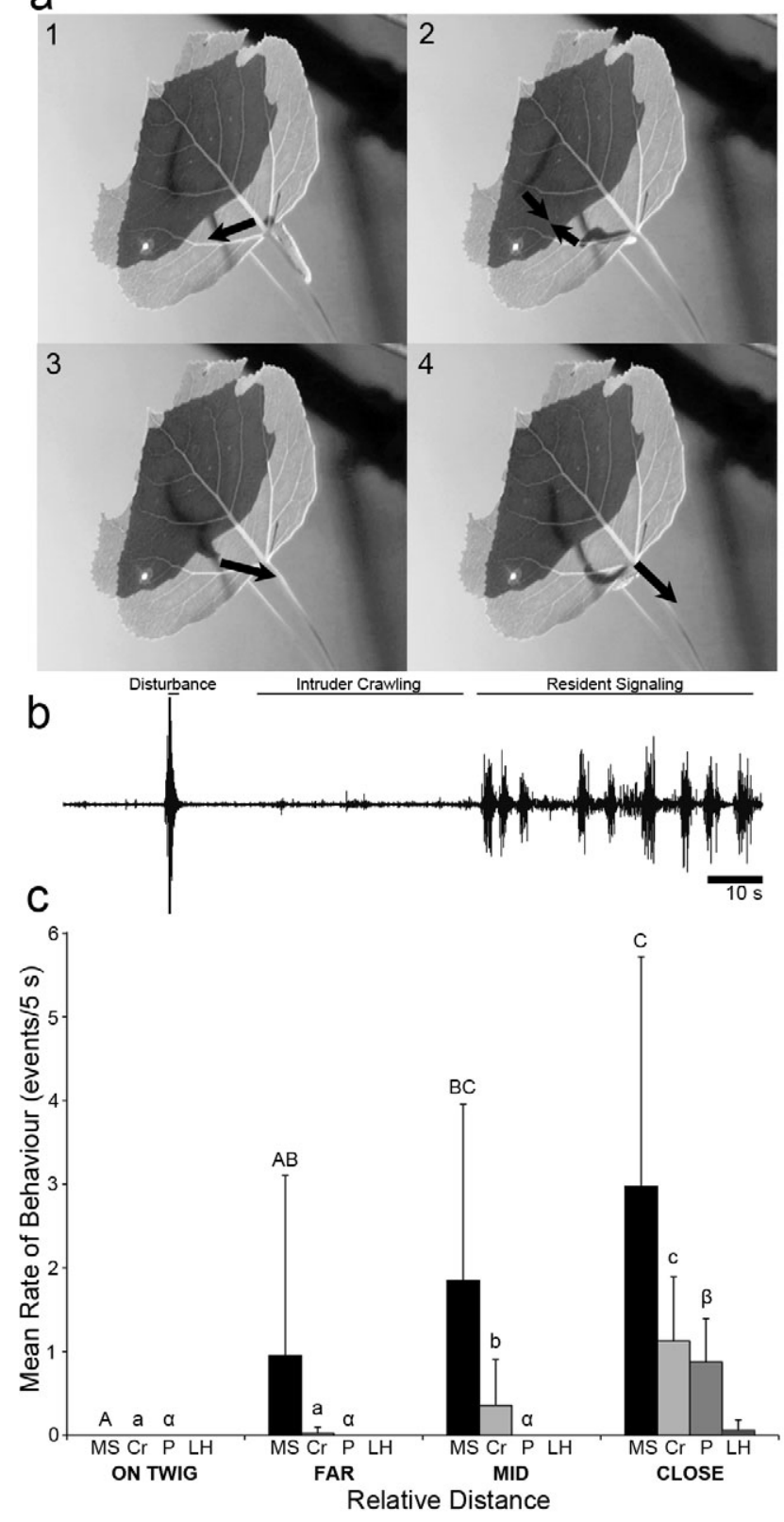

Fig. 2. Vibration signals and cues of Tethea or larvae during the course of a conspecific encounter. (a) - video frames illustrating the typical stages of an encounter: (1) intruder enters the leaf, (2) mid-point between the resident and intruder, (3) resident crawls towards the intruder and pushes intruder out of the shelter, (4) intruder leaves the leaf; (b) - vibration signals and cues produced by the resident in a single encounter, showing the disturbance caused by placing the intruder on the twig, intruder crawling and resident signaling; (c) - mean $(+\mathrm{SD})$ signaling and behavioural rates of residents at four distance categories of intruder approach (ON TWIG, FAR, MID, CLOSE). Capital letters (mandible scraping), lower-case letters (crawling) and Greek letters (pushing) show significant differences between distance categories within each signal type.

both residents and intruders throughout each trial. Trial durations were measured from the moment the intruder's head crossed the leaf-petiole junction to when one of the caterpillars crossed that junction while exiting the leaf. To determine how signaling and other territorial behaviours changed with respect
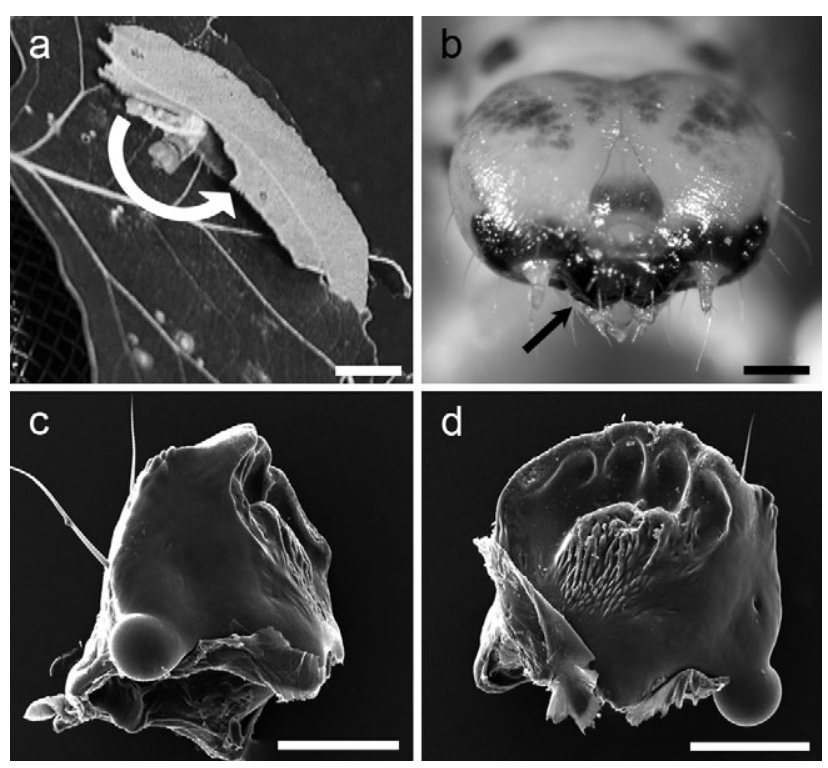

Fig. 3. Mandible scraping movements and structures in Tethea or larvae. (a) - superimposed images from a video clip illustrating the mandible scraping movement in a resident positioned at the entrance to its leaf shelter, arrow shows direction of movement (scale bar $=5 \mathrm{~mm}$ ); (b) - anterior view of a lateinstar head showing the location of the mandibles (arrow; scale bar $=0.5 \mathrm{~mm}) ;(\mathrm{c}, \mathrm{d})-$ scanning electron micrograph of the left (c) (lateral view; scale bar $=200 \mu \mathrm{m}$ ) and right (d) mandibles (ventral view; scale bar $=200 \mu \mathrm{m}$ ).

to distance between individuals, rates were measured at four stages of intruder approach - on twig (when the intruder is on the twig and has not yet passed the junction of the petiole), far (when the head of the intruder passed the junction of the petiole), mid (the mid-way point between the far and close distances) and close (the point when the intruder first made contact with the resident). Rates were measured by counting the number of behaviours over a 20 -s period from the beginning of the stage and calculated as the number of events per $5 \mathrm{~s}$. Grand means of rates for each behaviour type at each stage were calculated and compared using a Kruskal-Wallis one-way analysis of variance. Post hoc analyses were performed using pair wise Wilcoxon Rank Sum Tests.

\section{RESULTS}

\section{Shelter construction and occupation}

General observations were made on late instar larvae placed in glass containers with 2-3 sprigs of Populus sp., each with multiple leaves. Caterpillars constructed shelters by pulling together the broad surfaces of two adjacent leaves with silk, and fastening them together using 4-10 anchor points. In some instances the caterpillar used the side of the container to attach the leaf, which provided a window to observe the caterpillar's behaviour. The inner surface of one of the leaves was covered with a mat of silk (Fig. 1a) upon which the caterpillar rested. Caterpillars rested inside their shelters in a U-shaped position, and exited the leaf shelter from one opening to feed at the edge of one or both of the leaves forming the shelter (Fig. $1 b, c)$. 


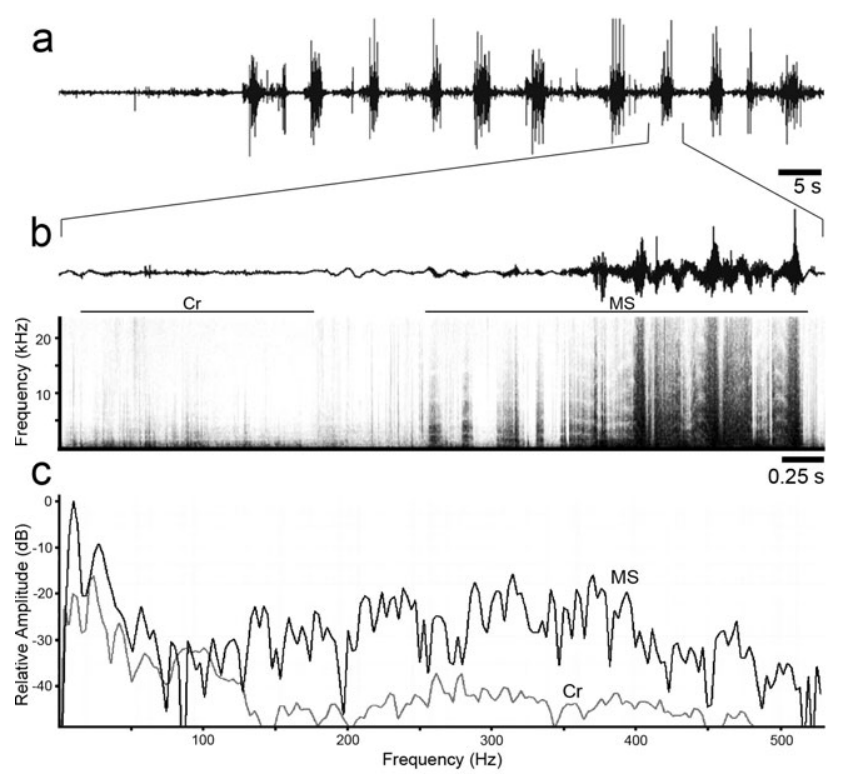

Fig. 4. Vibrations produced by Tethea or larvae during conspecific encounters. (a) - oscillogram illustrating a series of bouts produced by a leaf-shelter resident when approached by a conspecific intruder; (b) - segment expanded from (a) to show crawling vibrations ( $\mathrm{Cr}$; left) and a single bout comprising a series of six mandible scrapes (MS; right), with corresponding spectrogram; (c) - power spectra of a representative mandible scrape (MS), and crawling vibration $(\mathrm{Cr})$.

\section{Conspecific trials}

Staged interactions between a resident and intruder began with the resident either resting in its shelter, or feeding at the shelter edge. When the intruder was applied to the leaf twig with a paintbrush, a large amplitude disturbance was detected by the laser vibrometer but this did not affect the resident's behaviour (Fig. 2a, b). As the intruder approached the shelter, vibrations caused by crawling movements were detected by the laser. Residents did not respond until the intruder crossed the leafpetiole junction. The general response of a resident was to initially retreat into the shelter (if it had been feeding at the leaf edge), and then to begin scraping its mandibles on the leaf surface within the shelter (Figs 2, 3a). Mandible scraping by residents began at a latency of $50.2 \pm 33.1 \mathrm{~s}$ $(n=11)$ from the beginning of the trial (when the intruder's head crossed the petiole), at a mean distance of $2.4 \pm 5.0 \mathrm{~cm}(n=11)$ from the head of the intruder. Residents also exhibited physically aggressive behaviours during encounters, including crawling towards the intruder and pushing or laterally hitting the intruder with the head. Biting by the resident was observed during conspecific encounters, but was not quantified because it was difficult to verify when larvae were concealed between leaves. Intruders sought out the leaf opening and attempted to enter the shelter. However, intruders were not observed to mandible scrape or push. Trials lasted $127.9 \pm 104.3 \mathrm{~s}$ (mean $\pm \mathrm{SD}, n=11)$ and in all trials the intruder left the leaf (i.e., the resident is assumed to have "won" the trial). When two caterpillars encountered each other on a leaf without a shelter, no signaling or physi- cally aggressive behaviours were observed. The following sections focus first on the vibrations and their associated behaviours recorded during formal trials, and then on the rates of behaviours recorded during different stages of the encounter.

\section{Vibration characteristics and mechanisms}

Mandible scraping involves a movement of the head, thorax and first two abdominal segments in a lateral arc while scraping the opened mandibles across the leaf surface (Fig. 3). Mandibles have four rounded distal teeth on the incisor area and a ridged oral surface (Fig. 3). The mean \pm SD duration of a single scrape is $136.7 \pm 50.8 \mathrm{~ms}$ (range $=43.0-260.0 \mathrm{~ms}, n=40$ (5 signals each from 8 individuals). Mandible scrapes typically occur in bouts of $4 \pm 1$ scrapes (range $=1-14, n=48$ bouts from 11 individuals) with each bout lasting on average $1.18 \pm 0.38 \mathrm{~s}$ (range $=0.10-4.07 \mathrm{~s}, n=48$ bouts from 11 individuals). Time intervals between bouts range from 1.03 to $32.0 \mathrm{~s}$ (mean $\pm \mathrm{SD}=5.24 \pm 3.23 \mathrm{~s}, n=45$ intervals from 11 individuals). The amplitude of a single mandible scrape is on average $21.6 \pm 12.3$ times the baseline $(n=25$ signals from 5 individuals). Mandible scrapes have a dominant peak at $7.16 \pm 2.49 \mathrm{~Hz}$, with bandwidths of $4.8 \pm 0.3 \mathrm{~Hz}$ at $-3 \mathrm{~dB}$ and $9.4 \pm 1.9$ at $-10 \mathrm{~dB}(n=25$ scrapes from 5 individuals).

Other vibrations associated with encounters included those produced by crawling (Fig. 4) and pushing. Forward crawling involves a wave of longitudinal contractions that begins at the posterior end of the caterpillar and travels to the anterior end. The mean $\pm \mathrm{SD}$ duration of a single crawl is $1.4 \pm 0.53 \mathrm{~s}(n=7)$. The amplitude of a single crawl is on average $6.6 \pm 5.2$ times the baseline ( $n$ $=25$ crawling vibrations from 5 individuals). Crawling vibrations have a dominant peak at $12.3 \pm 8.4 \mathrm{~Hz}$, with bandwidths of $5.1 \pm 0.9 \mathrm{~Hz}$ at $-3 \mathrm{~dB}$ and $12.2 \pm 3.6 \mathrm{~Hz}$ at $-10 \mathrm{~dB}(n=5)$. Pushing is a variation of crawling, where the head of a resident makes physical contact with another caterpillar; therefore the temporal and spectral characters were the same for both behaviours.

Mandible scraping vibrations had a significantly higher signal to noise ratio than crawling (paired $t$-test, $t=3.84$, $P=0.018, \mathrm{DF}=4)$. Mandible scraping was also more repetitive than crawling or pushing, being produced in bouts that were repeated throughout the encounter.

\section{Rate changes of behaviours during encounters}

Resident behaviours observed during trials included mandible scraping, crawling, pushing and lateral hitting. The following describes how the rates of these behaviours change at four stages of the encounter (on twig, far, mid and close) (Fig. 2c). The rate of mandible scraping increased significantly as the intruder approached, from "on twig" to "mid" stages (Wilcoxon Rank Sums, $Z=$ $2.72, P=0.0065, n=11$ ) and from "far" to "close" (Wilcoxon Rank Sums, $Z=2.31, P=0.021$ ). Resident crawling increased significantly from "on twig" to "mid" stages (Wilcoxon Rank Sums, $Z=2.72, P=0.0065, n=$ 11), from "far" to "mid" (Wilcoxon Rank Sums, $Z=2.31$, $P=0.019, n=11$ ), and from "mid" to "close" (Wilcoxon 
Rank Sums, $Z=2.36, P=0.018, n=11$ ). Rates of pushing also escalated as the intruder approached, increasing significantly at the "close" stage (Wilcoxon Rank Sums, $Z=-4.21, P<0.001, n=11$ ). Lateral head hitting did not vary significantly across stages (KruskalWallis Test, $H=6.14, P>0.05, n=11$ ).

\section{DISCUSSION}

During conspecific interactions leaf vibrations were associated with behaviours of the resident (mandible scraping, pushing, crawling) and a conspecific intruder (crawling). We propose that mandible scraping vibrations by the resident are territorial signals, while vibrations produced by crawling and pushing are passive cues. We discuss (1) the difference between signals and cues; (2) support for the hypothesis that mandible scraping functions in territorial encounters; and (3) the evolutionary origins of these vibratory communication signals in caterpillars.

\section{When is a vibration a signal or a cue?}

A communication signal can be defined as any act or structure that changes the behaviour of another organism, has evolved for that purpose, and is effective because the receiver's response has also evolved (Bradbury \& Vehrencamp, 1998; Maynard Smith \& Harper, 2003). A cue on the other hand is described as a feature, animate or inanimate, that can be exploited by a receiver as a guide to future action (Hasson, 1994) but has not evolved for communication (Galef \& Giraldeau, 2001). Signals differ from cues by their increased conspicuousness (e.g., higher signal-to-noise ratio), redundancy (e.g., repetition of signals), and stereotypy (e.g., have a stereotypical duration) (Bradbury \& Vehrencamp, 1998; Maynard Smith \& Harper, 2003), all features that aid in the detection and recognition of the signal by the receiver. Based on these criteria, the vibrations produced by mandible scraping in $T$. or should be considered signals, as they have a significantly higher signal-to-noise ratio (conspicuousness) than crawling and pushing vibrations, are highly repetitive and are produced in repetitive bouts (redundancy). Mandible scrapes also have a wider bandwidth compared to background and crawling vibrations, with energy up to $500 \mathrm{~Hz}$ at $-30 \mathrm{~dB}$. It is proposed that receivers of plant-borne vibrations are attentive to frequencies above the low frequency vibrations generated by background noise sources (e.g., wind and rain) that are typically below $100 \mathrm{~Hz}$ (Barth et al., 1988; Caldwell et al., 2009). Thus, excitement of large amplitude and high frequency leaf vibrations by mandible scraping would render the signal more conspicuous.

Although we cannot determine from our experiments the cues used by the resident to detect the intruder, we propose that the resident detects the crawling vibrations of the approaching intruder because (i) the resident responded before it could see the intruder, and (ii) crawling vibrations produced by the intruder were always detectable by the laser when the resident responded.

\section{Do mandible scrapes function in territorial behaviour?}

Our results support the hypothesis that mandible scraping functions in territorial defense of leaf shelters. Support for this hypothesis comes from the following lines of evidence. First, mandible scraping was produced by residents of leaf shelters in all experimental trials, and intruders were never observed to signal. Second, caterpillars were never observed to signal while wandering on a leaf, even when encountered by a conspecific. This restriction of signaling or aggression to the confines of a territory is a common characteristic of territorial conflicts (Huntingford \& Turner, 1987). Third, signals are elicited by the intruder's approach. Mandible scraping was never observed before trials, while the resident was alone on the leaf, and only occurred when the intruder approached. Fourth, mandible scraping increased in rate as the intruder approached the resident. Gradation in signaling rate and an increase in levels of physical aggression as the intruder approaches the resident may act to express changes in the motivational state of the resident, and is a common feature of protracted territorial encounters (Brown, 1975; Baker, 1983; Maynard Smith \& Harper, 2003). Enquist et al. (1990) also argue that contests should begin with less costly but less informative acts that progress to more costly acts as the risk of threat increases. Thus, in $T$. or, when the intruder is at a far distance, it poses little threat and the resident begins with low cost signaling (lower rates) to reserve energy and avoid attracting predators. As the intruder approaches, the risk increases, and the resident uses more costly signals (increased rates). Higher signal repetition rates as the intruder approaches may also act to ensure the intruder receives the message by increasing the redundancy of the signal. Finally, resident signaling is followed by the intruder leaving shelter. Residents retained their shelters in all trials, and the intruder abandoned the occupied leaf in a short amount of time, which is often the case in pair wise contests over an indivisible resource where there exists an asymmetry in ownership (Baker, 1983; Maynard Smith \& Harper, 2003).

Why would a caterpillar be territorial against conspecifics? Like many other caterpillars, $T$. or invests in building a leaf shelter, which provides a more stable microclimate, protection from predators and displacement, and enhanced quality of food (Fukui, 2001). Shelters are also costly, requiring time, energy and material to build (Ruggiero \& Merchant, 1986; Fitzgerald et al., 1991; Berenbaum et al., 1993; Cappuccino, 1993; Fitzgerald \& Clark, 1994). Many caterpillars have evolved ways to maintain the use of their shelters while minimizing their costs, such as using empty shelters, attempting take over of occupied shelters, or by sharing them with con- and heterospecifics (Berenbaum et al., 1993; Cappuccino, 1993; Lill et al., 2007). Shelter sharing, however, often has associated costs and is not always favourable (Cappuccino, 1993; Lill et al., 2007). It is proposed that some caterpillars protect their energetic and time investments by defending their shelters from others using vibratory signals. There have been detailed reports of vibration-mediated territo- 
rial signals in 5 species from various families, including the Gracillariidae, Tortricidae and Drepanidae (Russ, 1969; Yack et al., 2001; Fletcher et al., 2006; Bowen et al., 2008; Scott et al., 2010a). The behaviour we have reported in this study is consistent with the behaviours observed in these other species. While further studies should examine whether $T$. or also responds to heterospecifics and if intruders ever take over shelters from residents, our current results support the hypothesis that signals are used to advertise territory ownership.

\section{Evolutionary origins of vibratory territorial signals}

In some lepidopteran larvae defense of leaf shelters involves mainly physical aggression, and in some cases this can escalate to serious injury or death of one of the contestants (Weyh \& Maschwitz, 1982; Okuda, 1989; Baker, 1983; Berenbaum et al., 1993). Territorial behaviour in $T$. or therefore could represent an intermediate form between species that use only physical aggression, and those using only ritualized aggression (i.e., signaling). Tethea or begins the encounter by signaling, but then changes to physical aggression as the intruder approaches. Although not observed in our study, this escalation to physical aggression has been observed in $T$. or, where the lack of suitable shelter sites in large populations has caused these larvae to resort to biting and killing one another (I. Hasenfuss, pers. comm.). Interestingly, it has recently been proposed that movements and vibratory cues associated with physically aggressive behaviours are evolutionary precursors to vibratory communication signals in caterpillars. Scott et al. (2010b) show that a highly ritualized signal (anal scraping) of some species derives from crawling towards an intruder of behaviourally less derived species such as $T$. or. Based on similarity of movement patterns, we propose that mandible scraping signals are derived from vibratory cues associated with physical aggression, such as lateral head hitting. Studies are currently underway to test this hypothesis.

ACKNOWLEDGEMENTS. We thank K. Silvonen for collecting moths, I. Hasenfuss for unpublished observations on $T$. or larvae, and two anonymous reviewers for constructive comments on the manuscript. Funding was provided by NSERC (Discovery Grant), CFI (New Opportunities) and OIT grants to JEY, and an NSERC Postgraduate Scholarship to JLS.

\section{REFERENCES}

BAKer R.R. 1983: Insect territoriality. Annu. Rev. Entomol. 28: 65-89.

Barth F.G., Bleckmann H., Bohnenberger J. \& Seyfarth E.A. 1988: Spiders of the genus Cupiennius Simon 1891 (Araneae, Ctenidae). II. On the vibratory environment of a wandering spider. Oecologia 77: 194-201.

Berenbaum M.R., Green E.S. \& Zangerl A.R. 1993: Web costs and web defense in the parsnip webworm (Lepidoptera: Oecophoridae). Environ. Entomol. 22: 791-795.

Bowen J.L., Mahony S.J., Mason A.C. \& YaCK J.E. 2008: Vibration-mediated territoriality in the warty birch caterpillar Drepana bilineata. Physiol. Entomol. 33: 238-250.

Bradbury J.W. \& Vehrencamp S.L. 1998: Principles of Animal Communication. Sinauer Associates, Sunderland, MA, 882 pp.
Brown J.L. 1975: The Evolution of Behavior. W.W. Norton \& Co., New York, 761 pp.

Caldwell M.S., McKaniel J.G. \& Warkentin K.M. 2009: Frequency information in the vibration-cued escape hatching of red-eyed tree frogs. J. Exp. Biol. 212: 566-575.

CAPpuCCINo N. 1993: Mutual use of leaf-shelters by lepidopteran larvae on paper birch. Ecol. Entomol. 18: 287-292.

COCROFT R.B. 2001: Vibrational communication and the ecology of group-living, herbivorous insects. Am. Zool. 41: 1215-1221.

Cocroft R.B. \& Rodriguez R.L. 2005: The behavioral ecology of insect vibrational communication. BioScience 55: 323-334.

DeVRIES P.J. 1990: Enhancement of symbioses between butterfly caterpillars and ants by vibrational communication. Science 24: 1104-1106.

DeVRIES P.J. 1991: Call production by myrmecophilous riodinid and lycaenid butterfly caterpillars (Lepidoptera): morphological, acoustical, functional, and evolutionary patterns. Am. Mus. Novit. 3025: 1-23.

Enquist M., Leimar O., Ljungberg Y.M. \& Segerdahl N. 1990: A test of the sequential assessment game: fighting in the cichlid fish Nannacara anomala. Anim. Behav. 40: 1-14.

FitzGerald T.D. \& CLARK K.L. 1994: Analysis of leaf-rolling behavior of Caloptilia serotinella (Lepidoptera: Gracillariidae). J. Insect Behav. 7: 859-872.

Fitzgerald T.D., Clark K.L., Vanderpool R. \& Phillip C. 1991: Leaf shelter-building caterpillars harness forces generated by axial retraction of stretched and wetted silk. J. Insect Behav. 4: 21-32.

Fletcher L.E., Yack J.E., FitzGerald T.D. \& Hoy R.R. 2006: Vibrational communication in the cherry leaf roller caterpillar Caloptilia serotinella (Gracillariodea: Gracillariidae). $J$. Insect Behav. 19: 1-18.

FUKUI A. 2001: Indirect interactions mediated by leaf shelters in animal-plant communities. Popul. Ecol. 43: 31-40.

Galef B.G. \& Giraldeau L.-A. 2001: Social influence on foraging in vertebrates: causal mechanisms and adaptive functions. Anim. Behav. 61: 3-15.

Hasson O. 1994: Cheating signals. J. Theor. Biol. 167: 223-238.

Hill P. 2009: How do animals use substrate-borne vibrations as an information source? Naturwissenschaften 96: 1355-1371.

Huntingford F. \& Turner A. 1987: Animal Conflict. Chapman and Hall (Animal Behaviour Series), London, 448 pp.

Lill J.T., Marquis R.J., Walker M.A. \& Peterson L. 2007: Ecological consequences of shelter sharing by leaf-tying caterpillars. Entomol. Exp. Appl. 124: 45-53.

Maynard Smith J. \& Harper D. 2003: Animal Signals. Oxford University Press, Oxford, $166 \mathrm{pp}$.

Newman E. 1884: An Illustrated Natural History of British Butterflies and Moths. Parts 1-2. W.H. Allen, London, 489 pp.

Окира T. 1989: Aggressive characteristics of diapausing larvae of a stem borer, Busseola fusca Fuller (Lepidoptera: Noctuidae) in artificially crowded conditions. Appl. Entomol. Zool. 24: $238-239$.

Pierce N.A., Braby M.F., Heath A., Lohman D.J., Mathew J., Rand D.B. \& Travassos M.A. 2002: The ecology and evolution of ant association in the Lycaenidae (Lepidoptera). Annu. Rev. Entomol. 47: 733-771.

Riegler K. 1999: Thyatiridae - Thyatiridés. In: Papillons et Leurs Biotopes: Espèces; Dangers qui les Menacent; Protection. Suisse et Régions Limitrophes. Tome 2. Pro Natura, Ligue Suisses pour la Protection de la Nature, Basel, pp. 447-476.

Ruggiero M.A. \& Merchant H.C. 1986: Estimated energy budget for a population of eastern tent caterpillars (Lepido- 
ptera: Lasiocampidae) in Maryland. Environ. Entomol. 15: 795-799.

Russ K. 1969: Beiträge zum Territorialverhalten der Raupen des Springwurmwicklers, Sparganothis pilleriana Schiff (Lepidoptera: Tortricidae). Pflanzenschutzberichte 40: 1-9.

Scoble M.J. 1992: The Lepidoptera: Form, Function and Diversity. Oxford University Press, Oxford, $404 \mathrm{pp}$.

SCOTT J.L., Bond S.M. \& YACK J.E. 2010a: Variation on a theme: Vibrational signaling in the rose hook-tip moth caterpillar, Oreta rosea. J. Insect Sci. 10: 54.

Scott J.L., Kawahara A.K., Skevington J.H., Yen S.-H., Sami A., SмIтH M.L. \& YACK J.E. 2010b: The evolutionary origins of ritualized acoustic signals in caterpillars. Nature Commun. 1, No. 4; doi: 10.1038/ncomms 1002 .
Stokoe W.J., Stovin G.H.T. \& South R. 1948: The Caterpillars of the British Moths: Including Eggs, Chrysalids \& Foodplants. Vol. 1. Warne, London, $381 \mathrm{pp}$.

THEAKston S.W. 1866: Theakston's Guide to Scarborough. S.W. Theakston, Scarborough, $234 \mathrm{pp}$.

Virant-Doberlet M. \& CoKL A. 2004: Vibrational communication in insects. Neotrop. Entomol. 33: 121-134.

WeYh R. \& Maschwitz U. 1982: Individual trail marking by larvae of the scarce swallowtail Iphiclides podalirius L. (Lepidoptera; Papilionidae). Oecologia 52: 415-416.

Yack J.E., Smith M.L. \& Weatherhead P.J. 2001: Caterpillar talk: Acoustically mediated territoriality in larval Lepidoptera. Proc. Natn. Acad. Sci. USA 98: 11371-11375.

Received May 3, 2011; revised and accepted April 2, 2012 